\title{
Study of Schlieren Optical Visualization Basics Technique and the Principle
}

\author{
Dahrum Samsudin ${ }^{1, a}$, Bukhari Manshoor ${ }^{1}$, M.D Anuar ${ }^{1}$, M.S Othman ${ }^{1}$,
}

\author{
Amir Khalid ${ }^{1, b}$
}

${ }^{1}$ Combustion Research Group (CRG), Centre for Energy and Industrial Environment Studies (CEIES), UniversitiTun Hussein Onn Malaysia, Parit Raja, BatuPahat, 86400 Johor, Malaysia adahrumsamsudin@yahoo.com, bamirk@uthm.edu.my

\begin{abstract}
This paper presents a schlieren optical visualization technique and its application in observation of the changes of intensity in real images. Schlieren optical visualization technique system is the unique technique because it produces a neutral image easily-interpretable image of refractive-indexgradient fields. The schlieren technique remains to be one of the most powerful techniques to visualize the flow and useful as a tool in order to observe the flow characteristics, fuel-air mixing, spray evaporation and flame development. The schlieren system provides a method to viewing the flow through the transparent media. This paper present the basics technique of schlieren system especially for Z-type and two mirror schlieren system. This optical visualization photography together with digital video camera will capture the detail spray evaporation, mixture formation and flame process.
\end{abstract}

Introduction The schlieren Photography technique is a visualization that used to capture the flow. This technique has been subjected of combustion research since 1800s. This method can capture spray evaporation, spray interference and mixture formation clearly with real images [1-3]. Schlieren photography is a visual technique, invented by the German physicist August Toepler in 1864; it is widely used to photograph the flow of fluids of varying density. The schlieren technique remain to be one of the most powerful technique to visualized the flow and it is relatively easy to implementation, high and variable sensitivity, low cost and its used conventional of light[4-5]. Schlieren technique also based on the light reflection and in this technique the light reflects by using concave mirror.

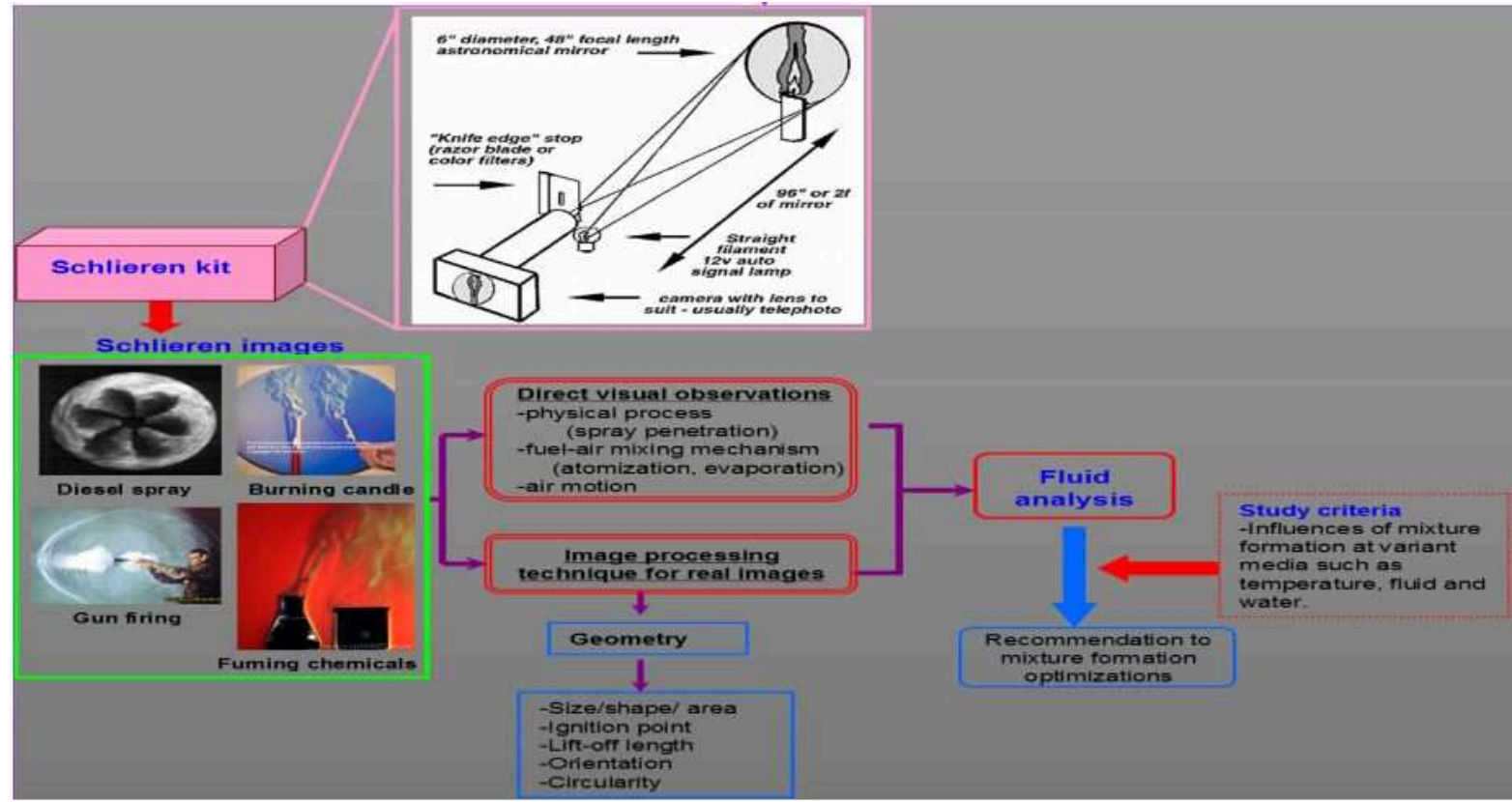

Figure 1: Influences of mixture formation on observation of combustion process [2] 
Figure 1 present a schematic description of the development of schlieren technique including the data browser to observe visualization on different gradient image at variant substance properties[69]. The graph shows that the flow parametric study can be used to investigate the relation between mixture formation and substance properties that can give valuable information during an evaporation process. Further, the mechanism and behavior of flame pattern will be analyzed by newly developed image processing technique.

\section{Experimental result \\ The importance of the knife-edge}

This section is finding the exact distance to place the knife-edge from the lens. The knife-edge is the factor that makes the configuration a Schlieren system. The importance of knife-edge is to block and it will form the image [2,5]. The corresponding image point will be dark compared to an image point corresponding to undistributed ray. By the way the luminance of a spot image will decrease or increased depend on the knife-edge position [5]. Figure 2 show the schlieren image of different distance from the camera lens. When the carriage is not positioned exactly at the focal point of the mirror, put the image will be disastroustrous. From image observation move the knife-edge somewhat or backward the exact can be found and different image exposure will get in different knife-edge position. From the image also too closed knife-edge and lens will yield a better image compares than a too far knife-edge from the lens.

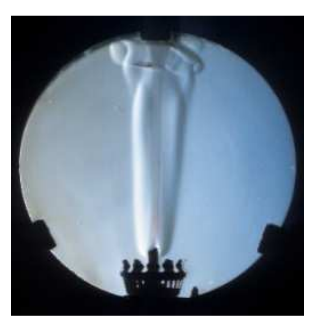

(a)

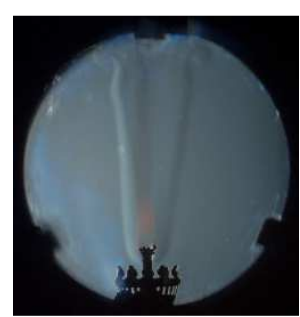

(b)

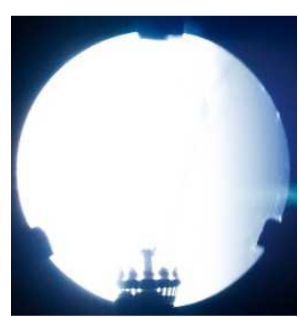

(c)

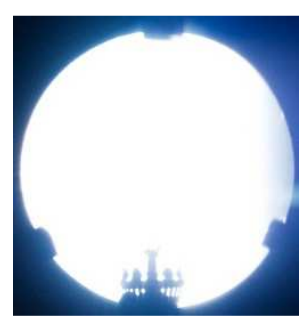

(d)

Figure 2: Influence of the position of the knife-edge with respect to the camera lens (a) $5 \mathrm{~mm}$ (b) $50 \mathrm{~mm}(\mathrm{c}) 100 \mathrm{~mm}(\mathrm{~d}) 150 \mathrm{~mm}$

\section{The effect of distance testing area placed in the picture}

A test area is one of the most important to find out because it can provide the best image when Schlieren image placed in exactly. In this result the Schlieren image is measured from mirror one to mirror two. As from the result in the Figure 3, at distance $20 \mathrm{~mm}$ and $140 \mathrm{~mm}$ the Schlieren image is sharp but it is seen two images because it to close with the mirror and it placed in the crossing light beam from one mirror to mirror two. From the image at the table below, at distance $40 \mathrm{~mm}$ and $60 \mathrm{~mm}$ is the sharpest image represent and this distance will use in this setup.

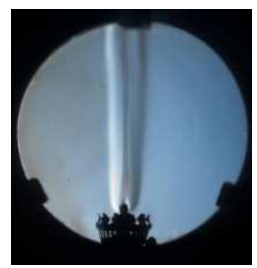

(a) $20 \mathrm{~mm}$

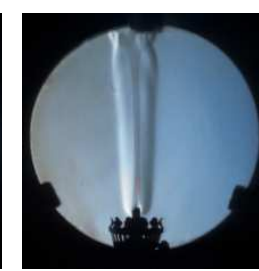

(b) $40 \mathrm{~mm}$

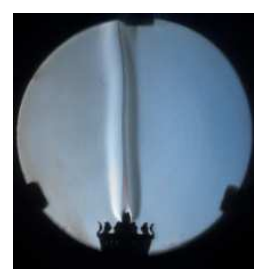

(c) $60 \mathrm{~mm}$

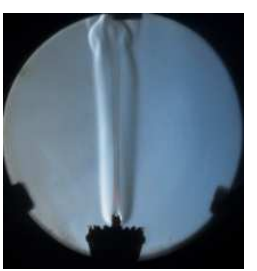

(d) $80 \mathrm{~mm}$

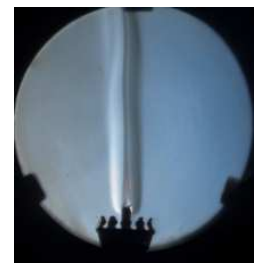

(e) $100 \mathrm{~mm}$

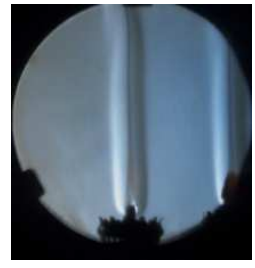

(f) $120 \mathrm{~mm}$

Figure 3: Influence of the distance of testing area on the Schlieren image in parallel light

\section{Optical visualization setting}

To get the best image camera setting is one the most important setting that will find out before run the experiment. Three basic camera setting will be discussed and it calls the exposure triangle. Exposure is the making of an image on a digital sensor by using light. In addition, three variables influences for making the exposure is Aperture, Shutter speed and ISO. Changing any one of this will affect the image exposure. So the exposure triangle is a relationship between aperture, shutter speed and ISO. 


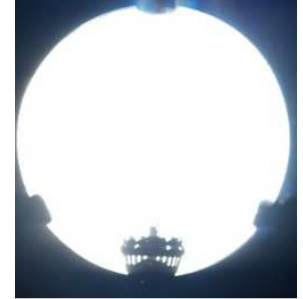

(a) shutter $=100 \mathrm{~s}$

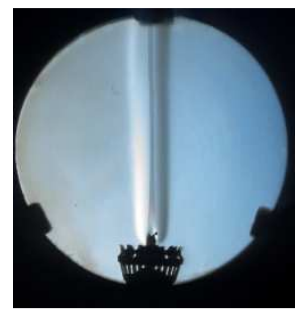

(d) Shutter $=2000 \mathrm{~s}$

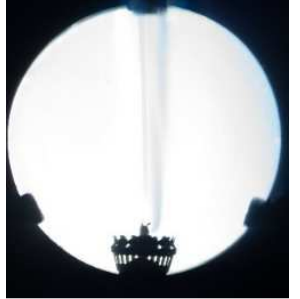

b) Shutter $=500 \mathrm{~s}$

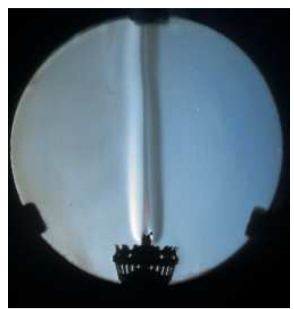

(e) Shutter $=3200 \mathrm{~s}$

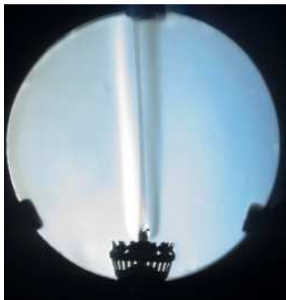

(c) shutter $=1000 \mathrm{~s}$

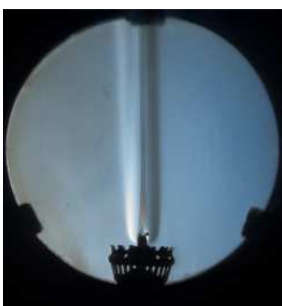

(f) shutter $=4000 \mathrm{~s}$

Figure 3: Influence of the shutter speed on the Schlieren image in parallel light

The first part of exposure triangle that will be discussed is shutter speed. The Shutter Speed indicates the speed in which the curtain opens then closes, and each shutter speed value also represents a "stop" of light. The shutter speed is measured in fractions of a second. Choosing the exact shutter speed will make the best exposure of the image that will be interpreted. As can see from the Figure 3 the fast shutter speed represents the better exposure compare than the slower shutter speed. Low shutter speed represents too brightness image and it will be better when shutter speed is increased. In shutter speed 1/4000s is the best image represent and this shutter speed will use in this setup. However choosing the shutter speed must be parallel to ISO and aperture (Exposure triangle) it important to control for adjusting how much light comes into the camera.

From this experiment, the result for different value of aperture is shown in Figure 4. The smaller value of aperture represent for the better exposure compare to the bigger value of aperture in the dark image. As known bigger value of aperture will be providing more detail image but in this technique the object come directly to the camera sensor by the light beam. This will affect the object because the diameter of the light beam is bigger than the diameter of the lens opening (aperture) due to the object produce, when using the bigger value of aperture just half of image can be seen.

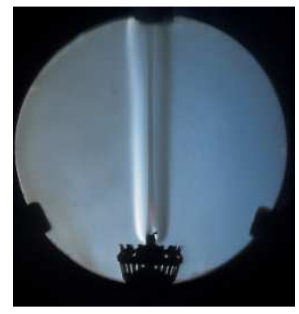

(a) Aperture $=\mathrm{f} 5.6$

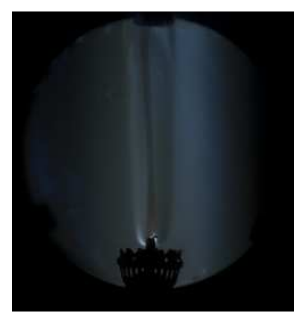

(d) Aperture $=\mathrm{fl} 4$

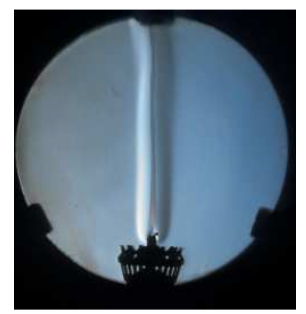

(b) Aperture $=$ f6.3

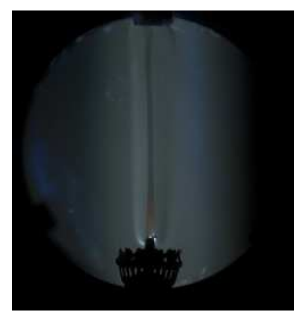

(e) Aperture $=\mathrm{f} 16$

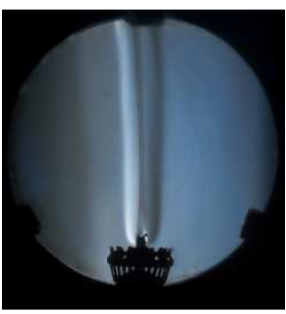

(c) Aperture $=$ f9

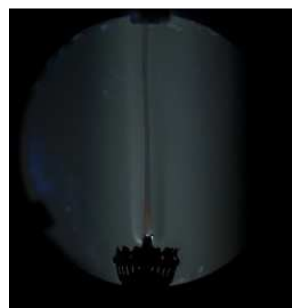

(f) Aperture $=\mathrm{f} 18$

Figure 4: Influence of the aperture on the Schlieren image in parallel light 


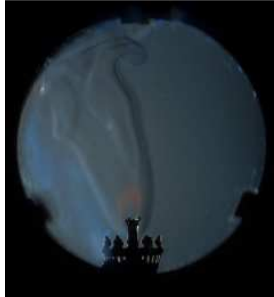

(a) ISO 100

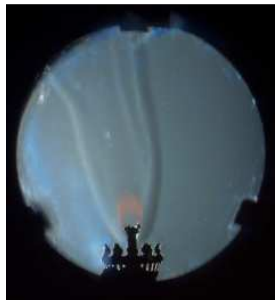

(b) ISO 500

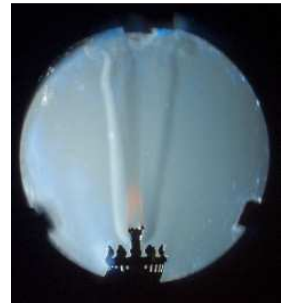

(c) ISO 1000

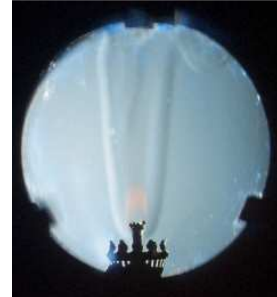

(d) ISO 1600

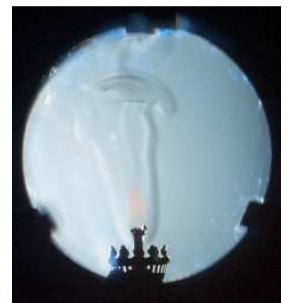

(e) ISO 2000

Figure 5: Influence of the ISO on the Schlieren image in parallel light

The third parts of exposure triangle are ISO rating determines the image sensor's sensitivity to light each value of rating show stop of light. A low ISO for Nikon D90 is LO.1 (100) is very insensitive and requires a lot of light. Actually its use on a sunny day and when want the best image quality. A high ISO is 3200 and it is more sensitive and requires less light. It can be used on an overcast day or for low-light, non-flash photography. Using high value of ISO will provide more grain also said more noise. But in this experiment with low noise image are required so ISO 100 will be used. Figure 5 shows the comparison image in different value of ISO value. From the image below increasing the ISO will make the image will overexposure and use the lowest ISO will be making the image underexposure.

\section{Conclusion}

This study is to setup Z-type two mirror Schlieren optical visualization technique for flame characteristics and spray penetration. The Schlieren technique is ideally suited for the visualization both of the spray and flame development. It is clear that schlieren optical visualization techniques are perfectly suitable for the study of the spray and flame development. This optical technique can be measure reflects the actual flow and it can be directly translated. The optical techniques used in this thesis allow a two dimensional, or integrated two dimensional measurements, which results in a clearly recognizable image and thus facilitates the interpretation of the results. Because every technique is based on the measurement of a different physical quantity, each technique highlights other aspects of the spray and flame development behavior

In this research, an experimental study to setup of Schlieren optical visualization for flame and spray characteristics. Discussions were made on the influences of the variant setting of the camera, knife-edge shape and distance for spray and flame for blending biodiesel. The results are summarized as follows;

a) Knife-edge must place in the correct position to make a sharp and clear image.

b) The Schlieren object must be put in $40 \mathrm{~mm}$ or $60 \mathrm{~mm}$ from the first mirror to find the sharpest image and placed the Schlieren image to close with the first or second mirror will make the shadow image.

c) Camera setting also important to ascertain before the actual experiment are being given.

\section{Acknowledgements}

The authors also would like to thank the Ministry of Higher Educations, Malaysia for supporting this research under Research Acculturation Grant Scheme (RAGS) Vot. R025 and Fundamental Research Grant Scheme (FRGS) Vot. 1054 


\section{Reference}

[1] G. S. Settles, Schlieren and Shadowgraph Techniques. 2001, p. 376.

[2] Amir Khalid, Keisuke Hayashi, Yoshiyuki Kidoguchi , Tomoaki Yatsufusa, "Effect of air entrainment and oxygen concentration on endothermic and heat recovery process of diesel ignition", (2011) SAE Technical Papers, DOI: 10.4271/2011-01-1834.

[3] Kidoguchi, Y., Miwa, K. Umemoto, K., Miwa, K., Omea, K., "A study on Multi-hole Spray interference and Mixture formation in Diesel Combustion", Trans of JSAE, 39-3, pp. 137-143, 2008

[4] Yoshihiro Kobyashi, Kenji Amagai, TomohikoFuruhta and Masataki Arai., "Behavior of PAH in a Doffusion Flame of Diesel Fuel", The Seventh International Conferance on Modeling and Diagnostics for Advanced Engine System (COMODIA 2008), July 28-31, 2008, Sappro, Japan

[5] Amir Khalid and Bukhari Manshoor, "Effect of High Swirl Velocity on Mixture Formation and Combustion Process of Diesel Spray", Applied Mechanics and Materials Vols. 229-231 (2012), Trans Tech Publications, Switzerland, pp 695-699.

[6] Amir Khalid and Bukhari Manshoor, "Analysis of Mixture formation and Flame Development of Diesel Combustion using a Rapid Compression Machine and Optical Visualization Technique", Applied Mechanics and Materials Vols. 315(2013), Trans Tech Publications, Switzerland, pp 293-298.

[7] Amir Khalid, N.Tamaldin, M. Jaat, M. F. M. Ali, B. Manshoor, Izzuddin Zaman, "Impacts of biodiesel storage duration on fuel properties and emissions", Procedia Engineering, volume 68, 2013, Pages 225 - 230, Elsevier, 2013, DOI: 10.1016/j.proeng.2013.12.172.

[8] Qian Wang, " Advanced Optical and 3D Reconstruction Diagnostics for Combustion and Fluids Research", The University of Sheffield Horibe, N., Annen, T., Miyazaki, Y. and Ishiyama, T., "Heat Release Rate and NOx Formation Process in Two-Stage Injection Diesel PCCI Combustion in a Constant-Volume Vessel", SAE paper 2010-01-0608, 2010.

[9] Ishiyama, T., Miwa, K. and Horikoshi, O., "A Study on Ignition Process of Diesel Spray", JSME International Journal, Series B, Vol.38, No.3, pp.483-489, 1995. 